Original Research Paper

\title{
Prediction on Land Market Value Based on the Real Estate Market in USA
}

\author{
Lei Wang \\ Department the Mathematics, The University of Southern Mississippi, USA
}

Article history

Received: 20-02-2017

Revised: 21-02-2017

Accepted: 23-05-2017

Email: fiona901587@yahoo.com

\begin{abstract}
The Land Market Value, defined as the total value of land price and quantity data are derived from data on housing values, is an important factor in the estimation of structure costs using price indexes for housing and construction costs. In this study, we gather and analyze 34 years' national data on past and present real estate transaction. According to the characteristics of raw data, we try to develop the potential Decomposition, Smoothing, ARIMA and other advanced forecasting models with appropriate transformations. Specifically, we employ an innovation space state underlying certain forecasting model. For regression analysis, we involves GDP, CPI, Construction Cost Index, population, unemployment rate, inflation rate and Purchasing Manage Index in multivariate statistical model. Most importantly, we obtain how to add value to business and apply skills set to real estate in a real world environment. The goal in providing crucial statistical method is to enable government and investors to make informed decisions regarding real estate.
\end{abstract}

Keywords: Forecasting Model, Land Market Value, Time Series Analysis

\section{Introduction}

This paper aims to provide important information of real estate market in USA and potential problems and opportunities or buyer and seller. As housing is a form of wealth, the purchase of a home represents an important investment and it is normally a hot topic for the scholars and investors. Because of scarcity, the fluctuation of land market value will have a great influence of the net worth of business and household. In this regard, Davis and Heathcote (2007) estimate that wings in residential land prices accounted for most of the variation in house prices over 1975-2006 for the United States as a whole. Davis and Palumbo (2008) reach the same conclusion for a large set of metropolitan areas over a somewhat shorter sample period, as do Bostic et al. (2007) in their detailed analysis of home price changes within a single metropolitan area (Wichita, Kansas). In addition, the land is an important component of wealth. Also, it is a source of variation in real estate prices and as collateral for loans, only a handful of studies have calculated land price indexes for the nation as a whole or for a broad set of cities. Davis and Heathcote (2007) and Davis and Palumbo (2008) estimate price indexes for residential land, while
Davis (2009) estimates indexes for both residential and commercial land. Also, Sirmans and Slade (2009) use transaction prices to calculate national land prices indexes. The data were collected on the basis of past and present real estate transactions and develop processes which guide future investment by demonstrating the true future value of the investment. To provide students with sufficient understanding and ability to model, analyze and develop forecasts for engineering and business decisions. The emphasis will be on quantitative methods.

\section{Background}

After food and medical care, housing is the largest consumer expenditure in the United states. In 1994, personal consumption expenditures on housing were about $\$ 2600$ per capita, or $14.9 \%$ of household budgets. Further, the bulk of expenditures in one of the next highest categories, household operations, are linked to housing. From the investment side, housing is the largest single form of fixed capital investment in the United States, comprising more than $\$ 9$ trillion, or roughly half of this nation's gross fixed private capital. Other than human capital, housing and land are more widely held than any other form of capital. 
Table 1. How housing market works

\begin{tabular}{|c|c|c|c|c|}
\hline Inputs & & Production & & Demand \\
\hline Land & $\mathrm{P}$ & Developers & $\mathrm{P}$ & \\
\hline Finance & $\mathrm{R}$ & Builders & $\mathrm{R}$ & Renters \\
\hline Infrastructure $\Rightarrow$ & I & $\Rightarrow$ Landlords $\Rightarrow$ & I & $\Rightarrow$ Homeowners \\
\hline Labor & $\mathrm{C}$ & Homeowners & $\mathrm{C}$ & (Income and population) \\
\hline Materials & $\mathrm{E}$ & & $\mathrm{E}$ & \\
\hline
\end{tabular}

In United States, as in most countries, the market for housing services can be approximated as a competitive market. Housing production activities have few barriers to entry or large economies of scale. Few landlords or developers are large enough to exert significant market power. The Table 1 showed the mechanism of housing market.

Housing is the largest asset of most American households, so the housing market profoundly affects the distribution of wealth; housing's location and tenure could well affect the behavior of its occupants. Hence, we work on how housing market works? In a good economic situation when house prices are consistently rising, most consumers can afford what is perceived to be full market value for a given property, because the inherent assumption is that value will continue to rise.

\section{Regression Analysis and Dynamic Regression Models}

For regression method, as shown in Fig. 1, we mainly measures how the land market value, in terms of GDP, CPI, construction cost index and unemployment rate, inflation rate, population and purchasing manage index, enables a relationship with the real estate market and investment.

Besides, we explore the quantitative and qualitative relationship among these economic variables at risk scenarios. Firstly, we developed two regression models with raw data and $\log$ transformation. After checking all the significance of all explanatory variables and residuals of autocorrelation, we obtain Equation 1 and 2. From the Equation 1, we may simply conclude that the land market value is highly related to IR, UR, CCI and PMI. When UR increased 1 unit and other variables keep unchanged, the land market value will decrease 218.85 million. For Equation 2, it involves more explanatory variables than Equation 1:

$$
\begin{aligned}
& L M V=-8400.287+574.933 I R \\
& -218.85 U R+154.035 C C I+30.048 P M I
\end{aligned}
$$

Where:

$$
\begin{aligned}
L M V= & \mathrm{f}(\mathrm{GDP}, \mathrm{CPI}, \mathrm{CCI}, \mathrm{UR}, \mathrm{IR}, \mathrm{PP}, \mathrm{PMI}) \\
L M V= & \text { Land market value (Aggregate market value of } \\
& \text { residential land) } \\
G D P= & \text { Gross Domestic Product (the total value of goods } \\
& \text { and services within a nation over a period) }
\end{aligned}
$$

$C P I=$ Consumer Price Index (a measure of the weighted average of prices of consumer goods and services)

$C C I=$ Construction Cost Index (Expense incurred by a contractor)

$U R$ = Unemployment Rate (a measure of the prevalence of unemployment)

$I R=$ Inflation Rate (the percentage increase in the price of goods and services)

$P P=$ Population (human beings in general or considered collectively)

$P M I=$ Purchasing Manager Index (an indicator of the economic health of the manufacturing sector)

Considering the multicollinearity within the multiple regressions, we only dropped the variables which are highly related to other variables in the regression, such as GDP and PP in Equation 1. Because such variables GDP and $\mathrm{PP}$ are capturing the effect of other variables. However, unemployment usually indicate more economic distress and lower production which causes lower demand for economic purchases including land. Hence, it shows the negative relation to the Land Market Value. Because of the big sample size, we keep some insignificant variables in our model, the effects of those variables, PMI and UR, are negligible. Also, we get rid of the effects of multicollinearity for the selected variables in Equation 1:

$$
\begin{aligned}
& L L M V=82.146-18.029 L P P+4.2 L C C I \\
& +4.45 L G D P+0.505 L U R=0.545 L P M I-0.148 L I R
\end{aligned}
$$

The log transformation of the regression model can help stabilize the variance. Hence, we try to fit the log transformed model of Equation 2. The transformed model statistical summary shown below.

However, from the Table 2 and 3, we may conclude that there are some evidence of autocorrelation in the residuals of Equation 1 and 2, it indicates there are some information from the data. Hence, we extended the regression method into the general class of dynamic regression models, which simply combined regression models with ARIMA errors. We take into account several formula as the theoretical foundation:

$$
\begin{aligned}
& y_{t}=\beta_{0}+\beta_{1} x_{1, t}+\cdots \cdots \cdots+\beta_{k} x_{k, t}+n_{t} \\
& \left(1-\phi_{1} B-\phi_{2} B^{2}\right) n_{t}=e_{t}
\end{aligned}
$$




$$
\begin{aligned}
& \left(1-1.5024 B+0.7229 B^{2}\right) n_{t}=e_{t} \\
& n_{t}=262.8185+1.5024 n_{t-1}-0.7229 n_{t-2}+e_{t}
\end{aligned}
$$

where, $n_{t}$ denotes the errors from the regression models and $e_{t}$ denotes the errors from the ARIMA model. Only the ARIMA model errors are assumed to be white noise.

Table 2. Regression table for Equation 1

\begin{tabular}{lllllll}
\hline Model & Coefficients & Standard error & T-value & Significance & VIF & Tolerance \\
\hline Constants & -8400.287 & 2857.725 & -2.94 & 0.006 & & \\
IR & 574.933 & 219.673 & 2.617 & 0.014 & 1.89 & 0.529 \\
UR & -218.850 & 136.198 & -1.607 & 0.119 & 1.098 & 0.911 \\
CCI & 154.035 & 12.589 & 12.236 & 0.00 & 1.635 & 0.612 \\
PMI & 30.048 & 37.207 & 0.808 & 0.426 & 1.37 & 0.726 \\
Model & R-squared & Adj R-squared & S.E of Est & Sample size & F-change & Significance \\
Equation 1 & 0.935 & 0.875 & 1220.773 & 34 & 50.570 & 0.00 \\
\hline
\end{tabular}

\begin{tabular}{|c|c|c|c|c|c|c|}
\hline Model & Coefficients & Standard error & T-value & Significance & VIF & Tolerance \\
\hline Constants & -0.172 & 1.156 & -0.149 & 0.883 & & \\
\hline LIR & 0.059 & 0.053 & 1.126 & 0.269 & 1.338 & 0.747 \\
\hline LUR & -0.281 & 0.132 & -2.122 & 0.043 & 1.12 & 0.893 \\
\hline LCCI & 2.169 & 0.12 & 18.088 & 0.00 & 1.299 & 0.770 \\
\hline LPMI & -0.085 & 0.245 & -0.346 & 0.732 & 1.153 & 0.867 \\
\hline Model & R-square & Adj R-squared & S.E of Est & Sample Size & F-value & Significance \\
\hline Equation 2 & 0.937 & 0.928 & 0.17765 & 34 & 107.374 & 0.00 \\
\hline
\end{tabular}

Table 3. Regression table for Equation 2

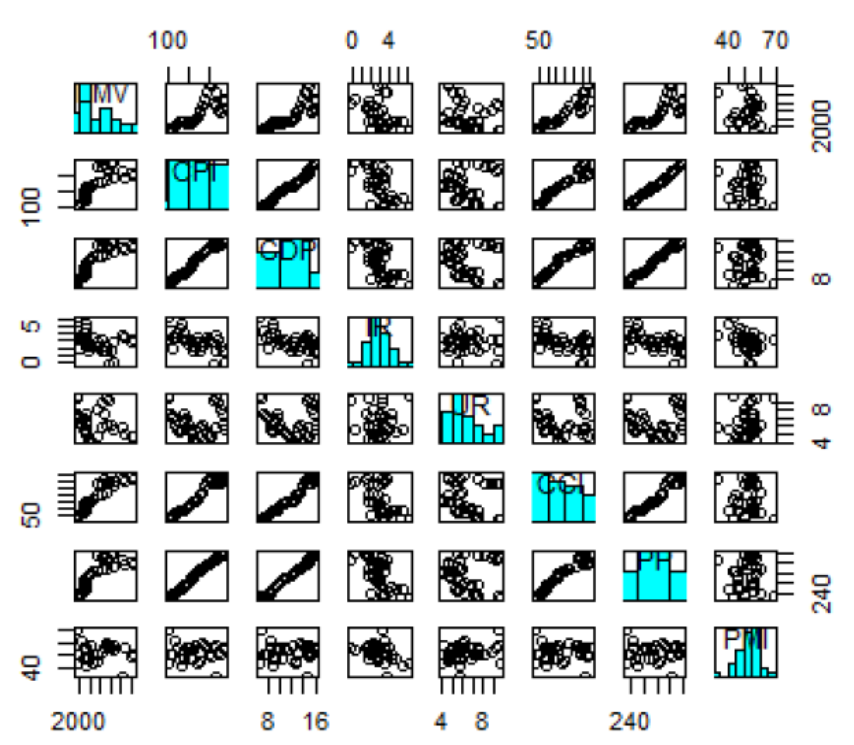

Fig. 1. LMV
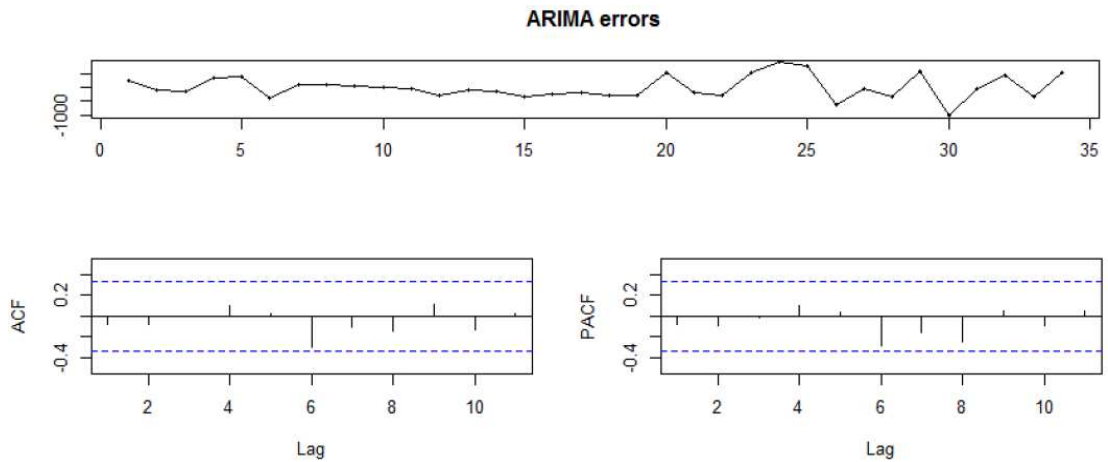

Fig. 2. Dynamic regression 


\section{Box.test X-squared df P-value Box.Ljung $14.0415 \quad 20 \quad 0.8284>0.05$}

From the plots and non-parametric tests of $e_{t}$ in Fig. 2, we may conclude that the residuals of the AR (2) from the regression model is stationary. Compared to three regression equations, the dynamic method is better than others.

\section{Time Series Decomposition and Smoothing Analysis}

For time series decomposition models, we have a couple of options, such as the classical additive decomposition, classical multiplicative decomposition and STL decomposition. The classical decomposition is basic and simple way to forecast the trend. We employ the simple exponential smoothing method, holt's linear method, exponential smoothing method and additive damped method and multiplicative damped method. Eventually, the exponential smoothing model could have better forecasting on the trend in Fig. 3.

For ETS(M,A,N) model, we take this into innovation by considering multiplicative error equations:

$$
\begin{aligned}
& y_{t}=\left(l_{t-1}+b_{t-1}\right)\left(1+\varepsilon_{t}\right) \\
& l_{t}=\left(l_{t-1}+b_{t-1}\right)\left(1+\alpha \varepsilon_{t}\right) \\
& b_{t}=b_{t-1}+\beta\left(l_{t-1}+b_{t-1}\right) \varepsilon_{t} \\
& \varepsilon_{t}=\frac{y_{t}-\left(l_{t-1}+b_{t-1}\right)}{l_{t-1}+b_{t-1}}
\end{aligned}
$$

where the $\varepsilon \sim \operatorname{NID}\left(0, \sigma^{2}\right), l_{t}$ denotes an estimate of the level of the series at time $t, b_{t}$ denotes an estimate of the trend (slope) of the series at time $t, \alpha$ denotes the smoothing parameter for level. $\beta$ denotes the smoothing parameter for the trend.

By the method of minimizing the "likelihood". We estimate the smoothing parameters $\alpha, \beta, b$ and $l$. In our model, the estimated parameters are $\alpha=0.9051, \beta$ $=0.9051, l=836.1576, b=388.3622$. The possible values that the smoothing parameters can take is restricted. Traditionally the parameters have been constrained to lie between 0 and 1 so that the equations can be interpreted as weighted averages. For the state space models, we have set $0<\alpha<\beta<1$.
Forecasts from Holt's method with exponential trend

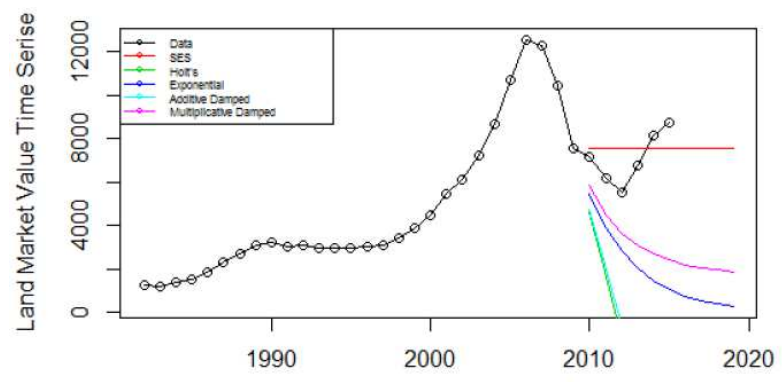

Fig. 3. Holt's method

\section{Time Series Analysis}

In the mature economies LMV illustrate the importance of land as a source of wealth, but in rapidly growing economies land has an even more significant role in determining economic welfare and a host of incentives for the performance of the economy. From the time series graph, we may find that the American land market value shows stable increase from 1982 to 2004, but from 2005 this number increased dramatically and peaked in $2006,12.55$. In fact, the economic crisis started in 2006 in USA, the economics crisis led to the increased interest, hence, the LMV rose rapidly. However, LMV decreased from 12.55 to 5.54 which is the relative lower level in 2012. The economy of USA experienced the great recession during this period. Until 2013, the situation recovered and this number rose to 7.594 in 2015 .

Conflicting results are very common when performing forecasting competitions between methods. As forecasting tasks can vary by many dimensions (length of forecast horizon, size of test set, forecast error measures, frequency of data, etc.), it is unlikely that one method will be better than all others for all forecasting scenarios. What we require from a forecasting method are consistently sensible forecasts and these should be frequently evaluated against the task at hand.

Obviously, in Fig. 4, Land Market Value is an increasing time series dataset. We tried original data and $\log$ transformation data to fit the ARIMA model. The Table 4 showed all the potential models. Eventually, the Box-Ljung test of residual met the assumption of the non-parametric, it indicates that autocorrelation come from the white noise, but the Log transformation reduced the RMSE significantly, which is almost near to 0.1 . Hence, we selected the Log ARIMA $(2,0,1)$ for forecasting model. 

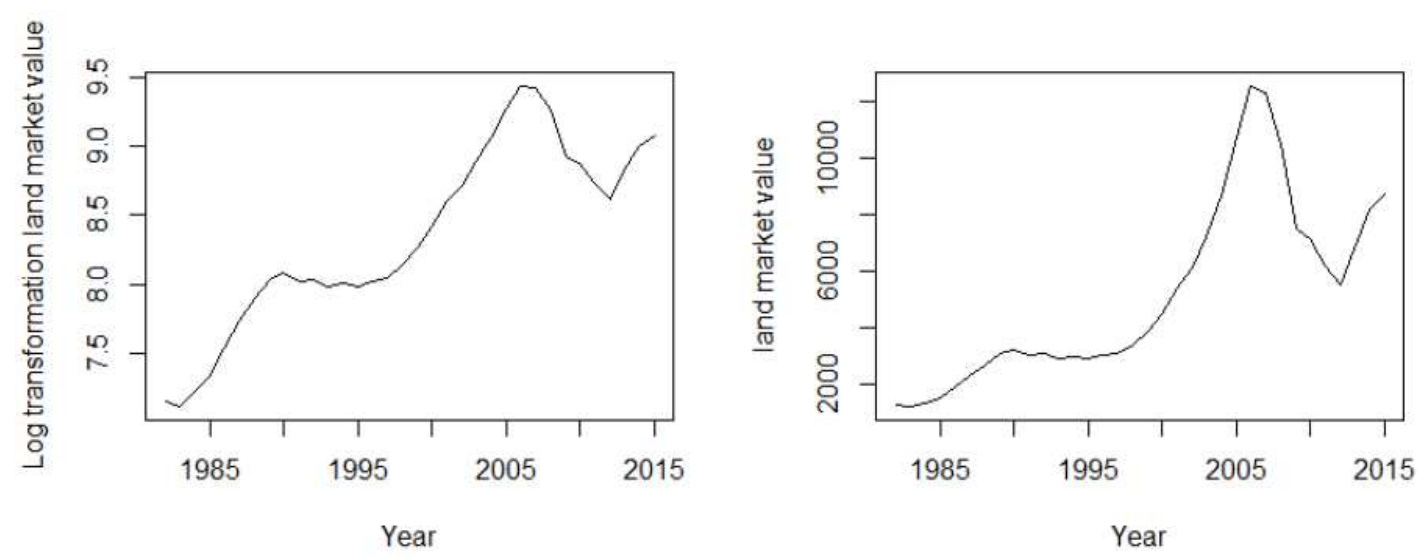

Fig. 4. tslmv

\section{Forecasts from ARIMA $(2,0,1)$ with non-zero m€}

Series residuals(TSM7)
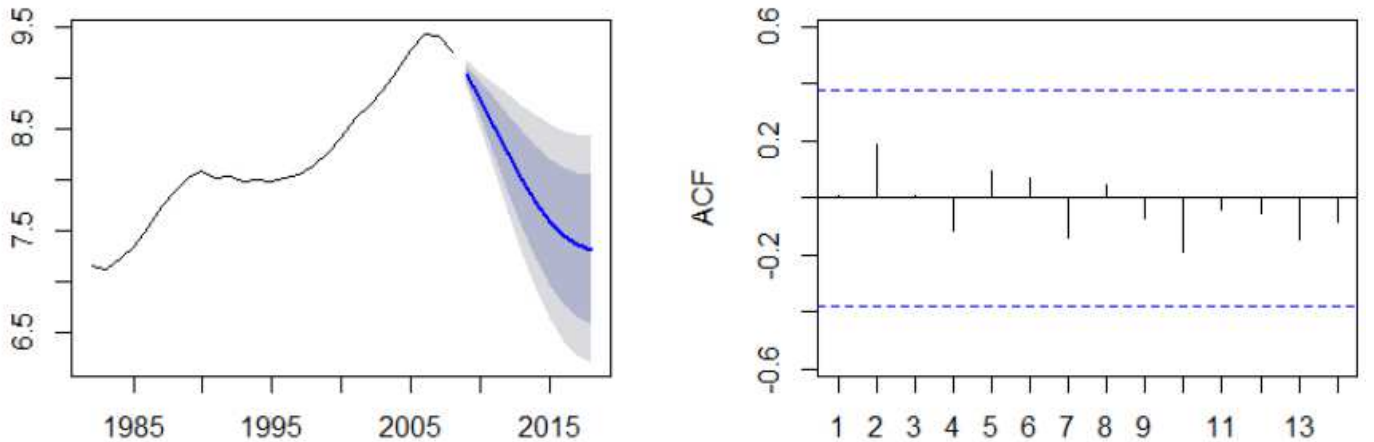

Lag

Fig. 5. TSLMV

Table 4. Comparison table

\begin{tabular}{lllllll}
\hline Model & ME & RMSE & MAE & MPE & MAPE & AIC \\
\hline Regression & $-1.103 \mathrm{e}-13$ & 1127.403 & 918.1104 & 0.6624 & 21.1810 & 586.37193 \\
Log Regression & $-2.7 \mathrm{e}-17$ & 0.1661 & 0.1489 & -0.0371 & 1.7665 & -12.84073 \\
Regression with AR (2) errors & -5.2326 & 590.5238 & 424.728 & -1.1753 & 7.9002 & 545.45 \\
ETS (M,A,N) & -91.4374 & 617.2248 & 339.1251 & -0.8840 & 408.4312 & 413.6146 \\
ARIMA (1,1,0) & 88.7736 & 713.7366 & 477.83 & 2.6121 & 7.973 & 532.83 \\
Log ARIMA (2,0,1) & 0.001 & 0.063 & 0.057 & 0.006 & 0.692 & N/A \\
\hline
\end{tabular}

Table 5. Forecasting ARIMA Model

\begin{tabular}{lllll}
\hline & Actual & Forecast & $95 \%$ L B & $95 \%$ U B \\
\hline 2009 & 8.928 & 9.041 & 8.917 & 9.165 \\
2010 & 8.878 & 8.792 & 8.523 & 9.061 \\
2011 & 8.73 & 8.526 & 8.1 & 8.952 \\
2012 & 8.620 & 8.259 & 7.678 & 8.84 \\
2013 & 8.821 & 8.006 & 7.281 & 8.731 \\
2014 & 9.006 & 7.781 & 6.931 & 8.631 \\
2015 & 9.075 & 7.594 & 6.642 & 8.546 \\
2016 & N/A & 7.453 & 6.424 & 8.481 \\
2017 & N/A & 7.361 & 6.28 & 8.442 \\
2018 & N/A & 7.321 & 6.209 & 8.433 \\
\hline
\end{tabular}




\section{Conclusion and Outlook}

As the Fig. 5 indicate that, for the data extending into 2015, Log ARIMA $(2,0,1)$ is the best forecasting model among others. We mainly evaluate forecasting models based on the two performance measures of RMSE and AIC. As was the case with the forecast in Table 5, land market value is projected to continue increase in the following years. It shows the stable increase in the future. This number will significantly rise to 7.3 in 2018 .

Land market value, both directly and indirectly, related to the housing market, commercial and residential buildings, construction industry and home price. The forecasting of land market value is more important and necessary for the economy of American, because the tendency of Land Market Value would be helpful for government and investor to examine the problem in housing market, make the appropriate policy and regulate the housing market. Thus, a given forecasting model did a good job of tracking the actual value of land market changes. On the other hand, forecasting techniques are widely used in the area of finance and housing market. As rapidly rising and housing prices are the hot topic in the growing number of metropolitans around the world. Most importantly, forecasting modeling is ever more significant in predicting the direction of future price.

\section{Acknowledgment}

We thank Dr. Longhofer for assistance with statistical modeling methodology and Sean Hennessy for comments that greatly improved the manuscript.

\section{Ethics}

This article is original and contains unpublished material. The corresponding author confirms that all of the other authors have read and approved the manuscript and no ethical issues involved.

\section{References}

Bostic, R.W., D.L. Stanley and L.R. Christian, 2007. Land leverage: Decomposing home price dynamics. Real Estate Econom., 35: 183-208. DOI: $10.1111 / \mathrm{j} .1540-6229.2007 .00187 . \mathrm{x}$

Davis, K., 2009. Financial regulation after the global financial crisis. Australian Econ. Rev., 42: 453-456. DOI: $10.1111 / j .1467-8462.2009 .00568 . x$

Davis, M.A. and G.P. Michael, 2008. The price of residential land in Large US Cities. J. Urban Econom., 63: 352-84.

DOI: $10.1016 /$ j.jue.2007.02.003

Davis, M.A. and H. Jonathan, 2007. The price and quantity of residential land in the United States. J. Monetary Econom., 54: 2595-2620. DOI: $10.1016 /$ j.jmoneco.2007.06.023

Sirmans, C.F. and B.A. Slade, 2009. National transaction-based land price indices. J. Real Estate Finance Econom., 45: 829-845.

DOI: $10.1007 / \mathrm{s} 11146-011-9306-3$

Appendix ${ }^{\mathrm{a}}:$ 1982-2015 Land Market Value Datasets ${ }^{\mathrm{b}}[\mathrm{H}]$

\begin{tabular}{|c|c|c|c|c|c|c|c|c|c|c|c|c|c|c|c|c|c|}
\hline Year & $\mathrm{LMV}^{\mathrm{c}}$ & $\mathrm{CPI}$ & GDP $^{\mathrm{d}}$ & IR & UR & $\mathrm{CCI}$ & $\mathrm{PP}$ & PMI & Year & LMV & CPI & GDP & IR & UR & $\mathrm{CCI}$ & $\mathrm{PP}$ & PMI \\
\hline 1982 & 1274.88 & 96.5 & 6.49 & 6.2 & 9.7 & 43.4 & 231.66 & 42.8 & 2000 & 4509.19 & 172.2 & 12.68 & 3.4 & 4 & 75.9 & 282.16 & 43.9 \\
\hline 1983 & 1232.25 & 99.6 & 7 & 3.2 & 9.6 & 44.70 & 233.79 & 69.9 & 2001 & 5428.39 & 177.1 & 12.71 & 2.8 & 4.7 & 79.7 & 284.97 & 45.3 \\
\hline 1984 & 1387.16 & 103.9 & 7.4 & 4.3 & 7.5 & 46.7 & 235.82 & 50.6 & 2002 & 6123.09 & 179.9 & 12.96 & 1.6 & 5.8 & 81.7 & 287.63 & 51.6 \\
\hline 1985 & 1546.45 & 107.6 & 7.71 & 3.6 & 7.2 & 47.9 & 237.92 & 50.7 & 2003 & 7208.82 & 184.13 & 13.53 & 2.3 & 6 & 85.9 & 290.11 & 60.1 \\
\hline 1986 & 1879.09 & 109.6 & 7.94 & 1.9 & 7 & 50.4 & 240.13 & 50.5 & 2004 & 8646.18 & 188.9 & 13.95 & 2.7 & 5.5 & 93.1 & 292.81 & 57.2 \\
\hline 1987 & 2297.13 & 113.6 & 8.29 & 3.6 & 6.2 & 52.7 & 242.29 & 61 & 2005 & 10708.93 & 195.3 & 14.37 & 3.4 & 5.1 & 100 & 295.52 & 55.1 \\
\hline 1988 & 2678.79 & 118.3 & 8.61 & 4.1 & 5.5 & 54.5 & 244.50 & 56 & 2006 & 12547.31 & 201.6 & 14.72 & 3.2 & 4.6 & 106 & 298.38 & 51.4 \\
\hline 1989 & 3097.56 & 124.8 & 8.85 & 4.8 & 5.3 & 56.4 & & 47.4 & 2007 & 12290.28 & & & 2.8 & 4.6 & 107 & & 49 \\
\hline 1990 & 3257.63 & 130.7 & 8.91 & 5.4 & 5.6 & 58 & 249.62 & 40.8 & 2008 & 10464.64 & 215.3 & 14.58 & 3.82 & 5.8 & 103.3 & 304.09 & 33.1 \\
\hline 1991 & 3050.34 & 136.2 & 9.02 & 4.2 & 6.8 & 58.2 & 252.98 & 46.8 & 2009 & 7537.82 & 214.5 & 14.54 & -0.32 & 9.3 & 98.10 & 306.77 & 55.3 \\
\hline 1992 & 3089.8 & 140.3 & 9.41 & 3 & 7.5 & 58.9 & 256.51 & 54.2 & 2010 & 7173.83 & 218.1 & 14.94 & 1.64 & 9.6 & 96.4 & 309.35 & 57.5 \\
\hline 1993 & 2948.23 & 114.5 & 9.65 & 3 & 6.9 & 61.8 & 259.92 & 55.6 & 2011 & 6184.28 & 224.9 & 15.19 & 3.14 & 8.9 & 97.4 & 311.72 & 53.1 \\
\hline 1994 & 2995.76 & 148.2 & 10.05 & 2.6 & 6.1 & 64.6 & 263.13 & 56.1 & 2012 & 5543.56 & 229.6 & 15.43 & 2.08 & 8.1 & 98.4 & 314.11 & 50.4 \\
\hline 1995 & 2945.05 & 152.4 & 10.28 & 2.8 & 5.6 & 67.3 & 266.28 & 46.2 & 2013 & 6777.04 & 233 & 15.92 & 1.46 & 7.4 & 104.8 & 316.5 & 56.5 \\
\hline 1996 & 3033.87 & 156.9 & 10.74 & 3 & 5.4 & 68.6 & 269.39 & 55.2 & 2014 & 8152 & 237.2 & 16.29 & 1.61 & 6.2 & 111.8 & 318.86 & 55.1 \\
\hline 1997 & 3120.62 & 160.5 & 11.21 & 2.3 & 4.9 & 70.6 & 272.65 & 54.5 & 2015 & 8737.11 & 242.1 & 16.3 & 0.1 & 5.5 & 100.37 & 320.99 & 53.5 \\
\hline 1998 & 3437.02 & 163.11 & 11.77 & 1.6 & 4.5 & 72.5 & 275.85 & 46.8 & & & & & & & & & \\
\hline 1999 & 3886.17 & 166.6 & 12.32 & 2.2 & 4.2 & 72.7 & 279.04 & 57.8 & & & & & & & & & \\
\hline
\end{tabular}

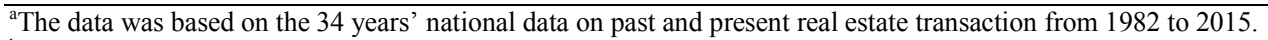

bttp://www.statista.com/statistics/188105/annual-gdp-of-the-united-states-since-1990/

Source: U.S. Bureau of Labor Statistics https://en.wikipedia.org/wiki/Main-Page.

${ }^{\mathrm{c}}$ The unit of land market value is million

${ }^{\mathrm{d}}$ The unit of GDP is trillion. 


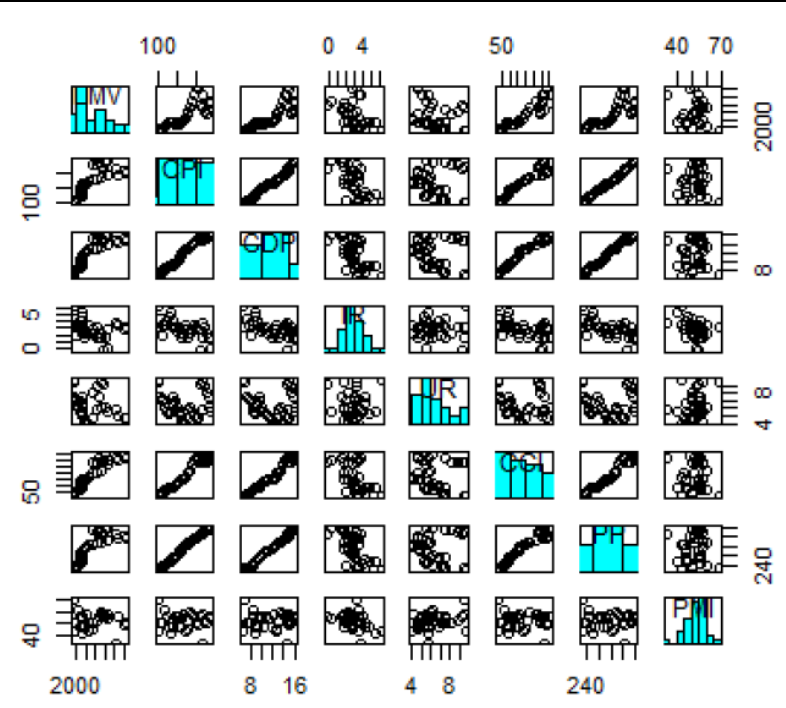

pane 1 . his $\mathrm{t}<-$ function $(\mathrm{x}, \ldots)\{$

us $r<-$ par ("us r")

on. exit (par (us r))

par (us $r=\mathrm{c}($ us r [1:2], 0,1))

$\mathrm{h} \$<-\$$ his $\mathrm{t}(\mathrm{x}$, plot $=$ FALSE, breaks $=$ "FD")

breaks $<-\mathrm{h} \$$ breaks

$\mathrm{nB}<-$ length (breaks)

$\mathrm{y}<-\mathrm{h} \$$ counts

$\mathrm{y}<-\mathrm{y} / \max (\mathrm{y})$

rect (breaks $[-\mathrm{nB}], 0$, breaks $[-1], \mathrm{y}, \mathrm{col}=$ "cyan", ...) $\}$

pairs (LMV. forecasting2[,(2:9)], diag. panel = panel. his t)

fit $<-$ Arima (LMV. forecasting3[,1], xreg = LMV. forecasting3[,2:8],

order $=\mathrm{c}(2,0,0))$

ts display (arima. errors (fit), main = "ARIMA errors")
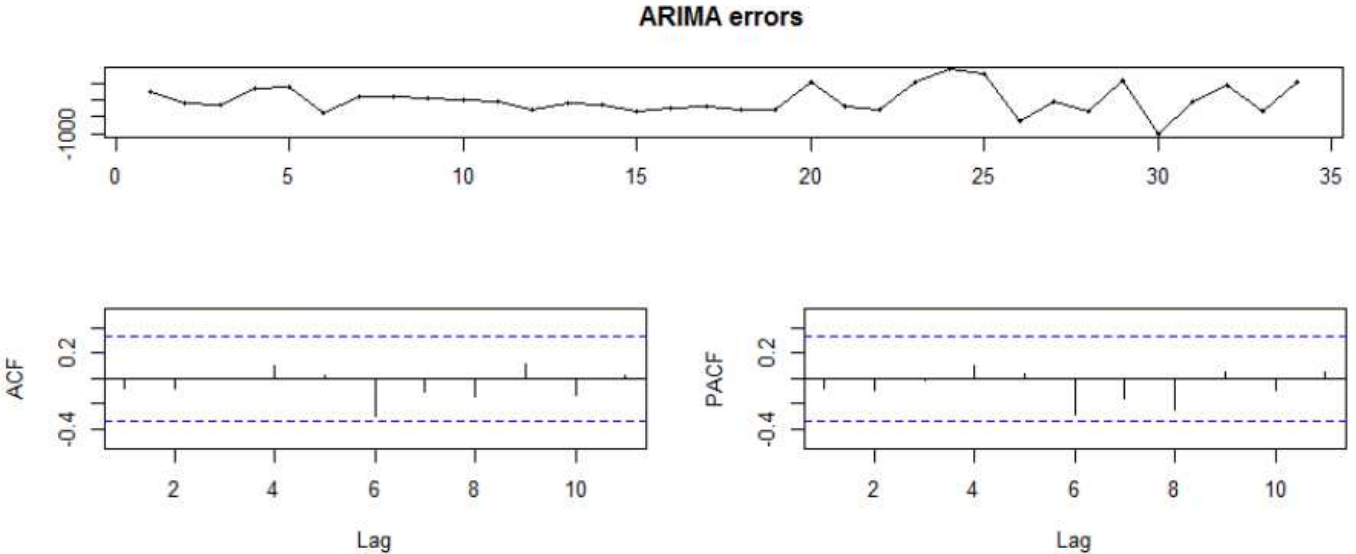

TSLMV1 $<-$ window $($ TSLMV, start $=1982$, end $=2008)$

fit $1<-$ se s (TSLMV1)

fit $<-$ holt (TSLMV1)

fit3 $<-$ holt $($ TSLMV1, exponential $=$ TRUE $)$

fit4 $<-$ holt (TSLMV1, damped $=$ TRUE)

fit5 $<-$ holt $($ TSLMV1, exponential $=$ TRUE, damped $=$ TRUE $)$

plot (fit2\$model\$state)

plot (fit 4 model\$state) 
plot (fit2\$model\$state)

flwd $=1$, plot. $\operatorname{conf}=$ FALSE)

lines $($ window $($ TSLMV, start = 2015), type $="$ o")

lines (fit 1 \$mean, $\mathrm{col}=2$ )

lines (fit2 $\$$ mean, col $=3$ )

lines (fit $4 \$$ mean, col $=5$ )

lines (fit5\$mean, col $=6$ )

legend ("topleft", lty $=1, \mathrm{pch}=1, \mathrm{col}=1: 6$,

c ("Data", "SES", "Holt's", "Exponential",

"Additive Damped", "Multiplicative Damped"), cex =0.75)

fit0 $<-$ ets(TSLMV1)

summary(fit0)

plot(forecast(fit0, $\mathrm{h}=8$ ),

Forecasts from Holt's method with exponential trend

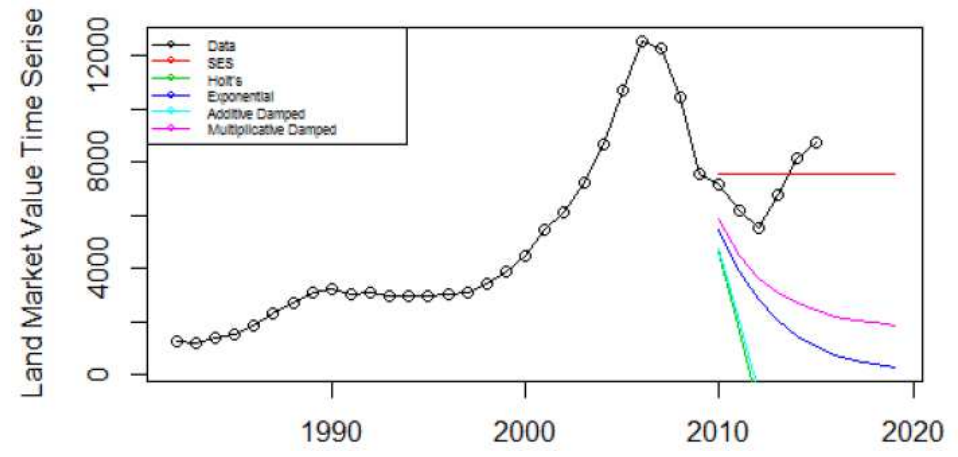

ylab = "Lank Market Value (millions)")

fit $1<-\operatorname{lm}(\mathrm{LMV} \sim \mathrm{IR}+\mathrm{UR}+\mathrm{CCI}+\mathrm{PMI}$, data $=\mathrm{LMV}$. forecasting3 $)$

summary(fit1)

accuracy(fit1)

fit2 $<-\operatorname{lm}($ LLMV $\sim$ LIR+LUR+LCCI+LPMI, data = LMV. forecasting3)

summary(fit2)

accuracy(fit2)

Box. test (residuals (fit), fit $\mathrm{df}=5$, lag $=10$, type $=$ "Ljung")
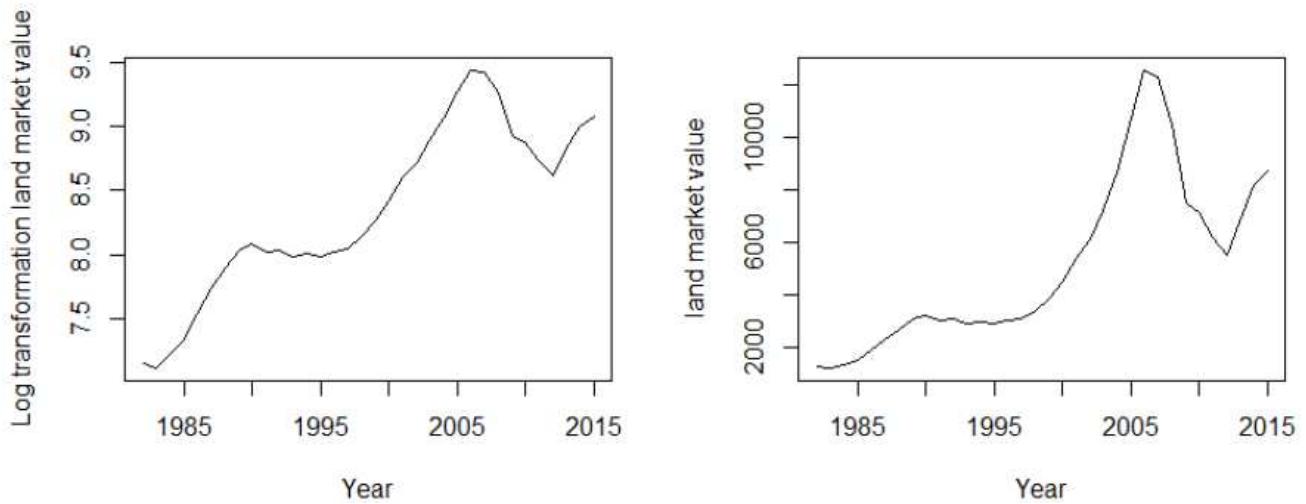

TSLMV $<-$ ts $($ LMV, start $=1982$, frequency $=1)$

LTSLMV $<-\log ($ TSLMV)

$\operatorname{par}(\mathrm{mfrow}=\mathrm{c}(1,2))$

plot (LTSLMV, ylab = "Log trans formation land market value", xlab = "Year")

plot $(\mathrm{TSLMV}, \mathrm{ylab}=$ "land market value", xlab = "Year") 


\section{Forecasts from ARIMA(2,0,1) with non-zero m€}

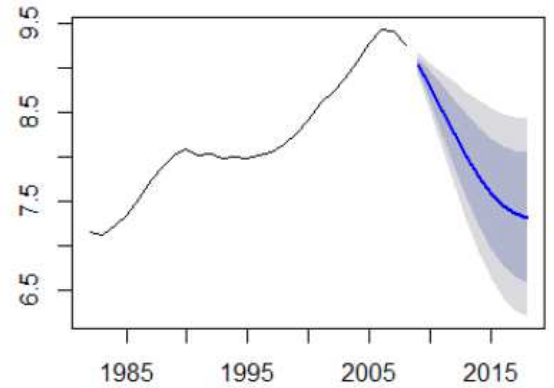

Series residuals(TSM7)

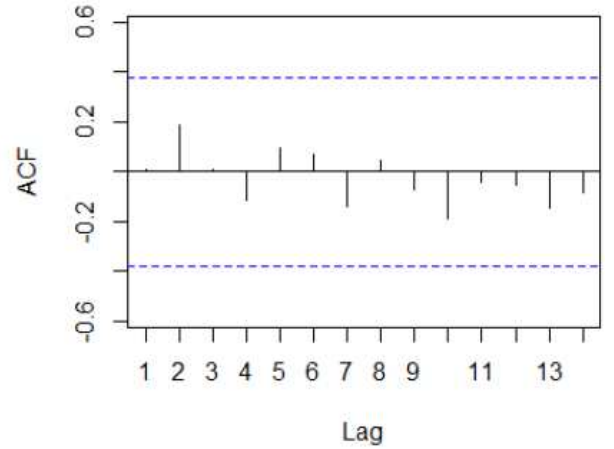

LTSLMV1 $<-$ window $($ LTSLMV, start $=1982$, end $=2008)$

TSM $1<-$ arima $($ TSLMV , order $=\mathrm{c}(1,1,0))$

Acf (residuals (TSM1))

summary(TSM1)

accuracy (TSM1)

forecast(TSM1)

plot (forecast (TSM1))

TSM7 <- arima $($ LTSLMV1, order $=\mathrm{c}(2,0,1))$

Acf (residuals (TSM7))

summary(TSM7)

accuracy (TSM7)

forecast (TSM7)

plot (forecast (TSM7)) 